\title{
Prevalence of Premature Ejaculation among Patients with Type 2 Diabetes in a Tertiary Health Institution: A Cross-Sectional Study
}

\author{
Michael Adeyemi Olamoyegun1*, Ala Oluwabukola Ayodele², Fagbemiro Emmanuel Yemi3, \\ Akinlade Taofiq Akinyele ${ }^{4}$
}

${ }^{1}$ Department of Internal Medicine; Endocrinology, Diabetes \& Metabolism Unit, Ladoke Akintola University of

Technology/LAUTECH Teaching Hospital, Ogbomoso, Oyo State, Nigeria

${ }^{2}$ Department of Medicine, BOWEN University/BOWEN Teaching Hospital, Ogbomoso, Oyo State, Nigeria

${ }^{3}$ Department of Medicine, Nile University of Nigeria, Abuja, Nigeria

${ }^{4}$ Department of Medicine, General Hospital, Odan, Lagos Island, Lagos, Nigeria

Email: *maolamoyegun@lautech.edu.ng

How to cite this paper: Olamoyegun, M.A., Ayodele, A.O., Yemi, F.E. and Akinyele, A.T. (2020) Prevalence of Premature Ejaculation among Patients with Type 2 Diabetes in a Tertiary Health Institution: A Cross-Sectional Study. Journal of Diabetes Mellitus, 10, 88-97.

https://doi.org/10.4236/jdm.2020.102008

Received: April 7, 2020

Accepted: May 16, 2020

Published: May 19, 2020

Copyright $\odot 2020$ by author(s) and Scientific Research Publishing Inc. This work is licensed under the Creative Commons Attribution International License (CC BY 4.0).

http://creativecommons.org/licenses/by/4.0/

\begin{abstract}
Background: Premature ejaculation (PE) is one of the sexual dysfunctions commonly present among patients with diabetes mellitus (DM), but rarely reported and not commonly investigated compared to erectile dysfunction. In this study, we aimed to investigate the prevalence of PE in a group of patients with type $2 \mathrm{DM}$ and explore possible determinants of its occurrence and its association with erectile dysfunction. Methods: This was a cross-sectional study of subjects recruited from the Diabetes clinic and whose sexual function was assessed using the premature ejaculation diagnostic tool (PEDT) and erection hardness score (EHS), who were in heterosexuals relationship and resides together with their wives and had no major organ failure or acute infection within the last 1 month. Other socio-demographic history and diabetes-related questions were assessed. Results: A total of 69 subjects were recruited. The prevalence of PE was $27.5 \%$ in the study. There was a significant inverse relationship between the prevalence of premature ejaculation and frequency of sexual intercourse. Almost half 14/30 (46.7\%) of those with erectile dysfunction had premature ejaculation. Diabetic patients with erectile dysfunction (ED) showed a significantly higher incidence of PE with significantly lower values of EHS. Higher level of fasting blood glucose was associated with higher prevalence of erectile dysfunction. Conclusions: The prevalence of PE was relatively high at 19/69 (27.5\%) among our type 2 diabetic patients. Hence, health care giver should always endeavour to ask about it even when patients do not volunteer the information.
\end{abstract}




\section{Keywords}

Type 2 Diabetes, Erectile Dysfunction (ED), Premature Ejaculation (PE), Prevalence

\section{Introduction}

Erectile dysfunction (ED) and ejaculatory disorders such as premature ejaculation (PE) are considered the most common types of sexual dysfunction (SD) in men. PE is defined as persistent or recurrent ejaculation with minimal sexual stimulation before, upon, or shortly after penetration or before the person wishes, causing distress and embarrassment to one or both partners and potentially affecting sexual relationship and overall well being [1]. It is one of man's most common, underreported and underestimated sexual problems. According to previous studies, the prevalence of PE ranged from $21 \%$ to $66 \%$ in the community [2] [3] [4], yet this medical condition remains a taboo subject in virtually every culture. Unlike ED which is more prevalent in older men, $\mathrm{PE}$ is considered one of the most common male SDs which occur with similar frequency in men, independent of age [1] [5] [6].

As at 2017, an estimated 422 million people had diabetes mellitus (DM) worldwide, accounting for about $9 \%$ of the adult population [7]. Diabetes is a chronic progressive disease usually complicated by both microvascular and macrovascular disorders. Its association with SD is well investigated, which occurrence may be due to vascular, neurological, hormonal, or psychologenic [8]. Most studies on SD in diabetic men have focused on ED hence, the prevalence and risk factors of other forms of SD including ejaculatory and orgasmic dysfunctions are not well known [9]. Although many studies have reported associations between DM and ED, however, only few studies have reported association between $\mathrm{DM}$ and PE, indicating that PE is more common in diabetics [10] [11]. Many pathologic mechanisms have been postulated for the occurrence of $\mathrm{PE}$ among diabetics, including autonomic neuropathy, psychological disorders like performance anxiety, depression and possibly lifestyle factors such as obesity [12].

Although many middle aged and older adult men with diabetes are sexually active, but the rate of sexual inactivity due to ED and PE among other sexual dysfunctions is higher than in non-diabetic men [13]. There are many health consequences of PE on the sexual and reproductive functions as well as psychological wellbeing. Hence, the American Diabetes Association (ADA) states that one of the comprehensive evaluations of the diabetes patients is the assessment of the potential presence of sexual dysfunctions including ED and PE [14]. Regrettably, this is hardly done during routine clinical practice in Nigeria due to the cultural or religion restraints on sexual discussions. This study therefore was aimed to determine the prevalence and risk factors associated with PE in men 
with type $2 \mathrm{DM}$ in Southwestern part of Nigeria.

\section{Methods}

We conducted a cross-sectional study among patients with type 2 diabetes aged 24 years and above who attends Diabetic clinic at a tertiary hospital, South West Nigeria. The study was conducted between April and September 2018. Patients were recruited if they had attended the clinic for at least 3 months and met the recruitment criteria. The inclusion criteria were men who were in heterosexual relationship cohabiting with their wives and have no major organ failure or acute infection within the last 1 month. A convenient sample size of eighty (80\} men who met the inclusion criteria were approached to be included as participants, but only sixty seven (69) who agreed and completed the questionnaire were analyzed. The participants were asked to complete a set of self-administered questionnaire (this was translated to Yoruba language for those who could not understand English) which consisted of questions on socio-demographic parameters, diabetes history and sexual history. Sexual history was assessed with Premature Ejaculation Diagnostic tool (PEDT), and Erection Hardness Score (EHS) questionnaires. The PEDT consists of five questions that address the following five domains: ejaculation control, frequency of PE, ejaculation with minimal sexual stimulation, distress and interpersonal difficulty. Each question has five responses and the scores of each question range from 0 to 4 with a minimum total score of 0 to a maximum score of 20. A low score suggest a low probability of having PE. The total scores are categorized into "no PE" $(\leq 8)$, probable PE ( 9 - 10), and PE ( $\geq 11)$. The EHS is a robust, single-item, self-reported tool that scores erection hardness on a four-point scale and can be used in daily clinical practice [15]; it was developed by Goldstein et al. in the sildenafil clinical trial program [16]. Briefly, EHS1 indicates erection hardness at sexual stimulation as larger but not hard, EHS2 indicates hard but not hard enough for penetration, EHS3 indicates hard enough for penetration but not completely hard, and EHS4 indicates completely hard and fully rigid [17].

Data Analysis: Statistical analysis of collected data was performed using SPSS version 20. Data was presented as mean \pm standard deviation (SD) or as numbers and percentages. A chi-square test was used to investigate association between possible predicting factors and occurrence of premature ejaculation. In all statistical tests, a value of $\mathrm{P}<0.05$ was considered significant.

Ethical approval for the study was obtained from the Ethics and Research Committee of the LAUTECH teaching hospital, Ogbomoso and each participant gave a verbal consent to be recruited as study participants.

\section{Results}

A total of 69 patients were recruited for the study. The mean age of the participants was $40.15 \pm 9.58$ years, and mean body mass index (BMI) was $26.92 \pm 3.99$ $\mathrm{kg} / \mathrm{m}^{2}$. Other socio-demographic data are as shown in Table 1. Premature ejaculation was found in 19 patients giving a prevalence of $27.54 \%$. 
Table 1. Sociodemographic characteristics of the study participants.

\begin{tabular}{cc}
\hline Variable & Mean \pm SD \\
\hline Age (years) & $40.15 \pm 9.58$ years, \\
Weight $(\mathrm{Kg})$ & $68.22 \pm 10.63$ \\
Height $(\mathrm{m})$ & $1.59 \pm 0.07$ \\
BMI $\left(\mathrm{kg} / \mathrm{m}^{2}\right)$ & $26.92 \pm 3.99$ \\
WC $(\mathrm{cm})$ & $81.42 \pm 17.49$ \\
HC $(\mathrm{cm})$ & $91.01 \pm 18.97$ \\
\hline
\end{tabular}

Keys: BMI-Body mass index; WC-Waist circumference; HC-Hip circumference.

The average frequency of sexual intercourse was $7.0 \pm 5.49$ (median-5.0, IQR-7.0) times/month. This frequency decreased with age (10.0 \pm 4.32 in $\leq 25$, $8.28 \pm 5.79$ in the $26-35$ years, $6.35 \pm 5.11$ in the $36-45$ years, $5.50 \pm 5.11$ in the 46 - 55 years, $\mathrm{P}=0.004$ ).

Table 2 shows the distribution of premature ejaculation among the patients. It was found in 1 (50\%) of those less than 25 years old, 5 (20.8\%) of those between 26 and 35 years old, 6 (23.1\%) of those between 36 and 45 years old, 2 (18.2\%) of those between 46 and 55 years old, and 1 (20.0\%) of those between 56 and 65 years old. There was a somewhat significant relationship between the frequency of sexual intercourse and premature ejaculation, the condition was found in $21.1 \%$ of those who have intercourse $<3$ times, $34.6 \%$ of those who have it $4-8$ times, $30.0 \%$ of those who have it $9-12$ times, and $20.0 \%$ of those who have it $>12$ times in a month.

The prevalence of erectile dysfunction was $60 \%$, although majority had mild to moderate ED. Premature ejaculation, as assessed by PEDT was present in $24.7 \%$ of the participants.

Figure 1 shows the relationship between frequency of sexual intercourse and age; as the age increases the frequency of sexual intercourse reduces. In the vein, as the EHS score increases, the frequencies of sexual intercourse sessions had by patient increases, Figure 2.

On the association of premature ejaculation with socio-demographic parameters, the only factor that determines premature ejaculation is the frequency of sexual activity, i.e. premature ejaculation is significantly related to the frequency of sexual intercourse, (Table 2).

Table 3, represent the relationship between erectile dysfunction and premature ejaculation; of the 17 participants that had premature ejaculation, 14/17 (82.4\%) also had erectile dysfunction.

\section{Discussion}

The premature ejaculation diagnostic tool (PEDT) which was developed in 2007 [18], has been validated in several populations [19] [20] [21]. The prevalence of premature ejaculation in our study was about $27.5 \%$. This value was less than 
Table 2. The distribution of premature ejaculation among the study participants.

\begin{tabular}{|c|c|c|c|}
\hline Variable & Number & Frequency of PE (\%) & $\mathrm{p}$-value \\
\hline \multicolumn{4}{|l|}{ Age class } \\
\hline$\leq 25$ & 2 & $1(50.0)$ & \multirow{5}{*}{0.703} \\
\hline $26-35$ & 26 & $6(23.1)$ & \\
\hline $36-45$ & 25 & $9(36.0)$ & \\
\hline $46-55$ & 11 & $2(18.2)$ & \\
\hline $56-65$ & 5 & $1(20.0)$ & \\
\hline \multicolumn{4}{|l|}{ Educational status } \\
\hline Primary & 9 & $3(33.3)$ & \multirow{4}{*}{0.330} \\
\hline Secondary & 14 & $1(7.1)$ & \\
\hline Tertiary & 44 & $14(31.8)$ & \\
\hline Postgraduate & 2 & $1(50.0)$ & \\
\hline \multicolumn{4}{|l|}{ Occupational status } \\
\hline Artisan & 10 & $2(20.0)$ & \multirow{6}{*}{0.849} \\
\hline Petty trader & 5 & $1(14.3)$ & \\
\hline Civil servant & 34 & $10(29.4)$ & \\
\hline Business & 3 & $1(33.3)$ & \\
\hline Private sector & 15 & $5(35.7)$ & \\
\hline Retiree & 2 & $1(50.0)$ & \\
\hline \multicolumn{4}{|l|}{ Monthly income } \\
\hline$\leq 20,000$ & 30 & $10(33.3)$ & \multirow{5}{*}{0.114} \\
\hline $20,001-50,000$ & 11 & $5(45.5)$ & \\
\hline $50,001-100,000$ & 14 & $7(50.0)$ & \\
\hline $100,001-150,000$ & 6 & $2(33.3)$ & \\
\hline $150,001-200,000$ & 5 & $1(20.0)$ & \\
\hline \multicolumn{4}{|l|}{ Smoking history } \\
\hline Yes & 14 & $4(28.6)$ & \multirow[t]{2}{*}{0.582} \\
\hline No & 55 & $15(27.3)$ & \\
\hline \multicolumn{4}{|l|}{ Alcohol history } \\
\hline Yes & 35 & $11(31.4)$ & \multirow[t]{2}{*}{0.322} \\
\hline No & 34 & $8(23.5)$ & \\
\hline \multicolumn{4}{|l|}{ Coffee history } \\
\hline Yes & 15 & $6(40.0)$ & \multirow[t]{2}{*}{0.184} \\
\hline No & 54 & $13(24.1)$ & \\
\hline \multicolumn{4}{|l|}{ Cola nut history } \\
\hline Yes & 11 & $3(27.3)$ & \multirow[t]{2}{*}{0.648} \\
\hline No & 58 & $16(27.6)$ & \\
\hline \multicolumn{4}{|c|}{ Frequency of SI (per month) } \\
\hline$<3$ times & 20 & $4(20.0)$ & \multirow{4}{*}{$<0.001$} \\
\hline $4-8$ times & 27 & $9(33.3)$ & \\
\hline $9-12$ times & 11 & $3(27.3)$ & \\
\hline$>12$ times & 11 & $2(18.2)$ & \\
\hline
\end{tabular}

Key: SI-sexual intercourse.

Table 3. Association between premature ejaculation and erectile dysfunction.

\begin{tabular}{llcc}
\hline & & \multicolumn{2}{c}{ Premature Ejaculation } \\
\cline { 3 - 4 } & & No & Yes \\
\hline \multirow{2}{*}{ Erectile dysfunction } & No & 20 & 3 \\
& Yes & 30 & 14 \\
\hline
\end{tabular}




\section{Frequency of sexual intercourse by age categories}

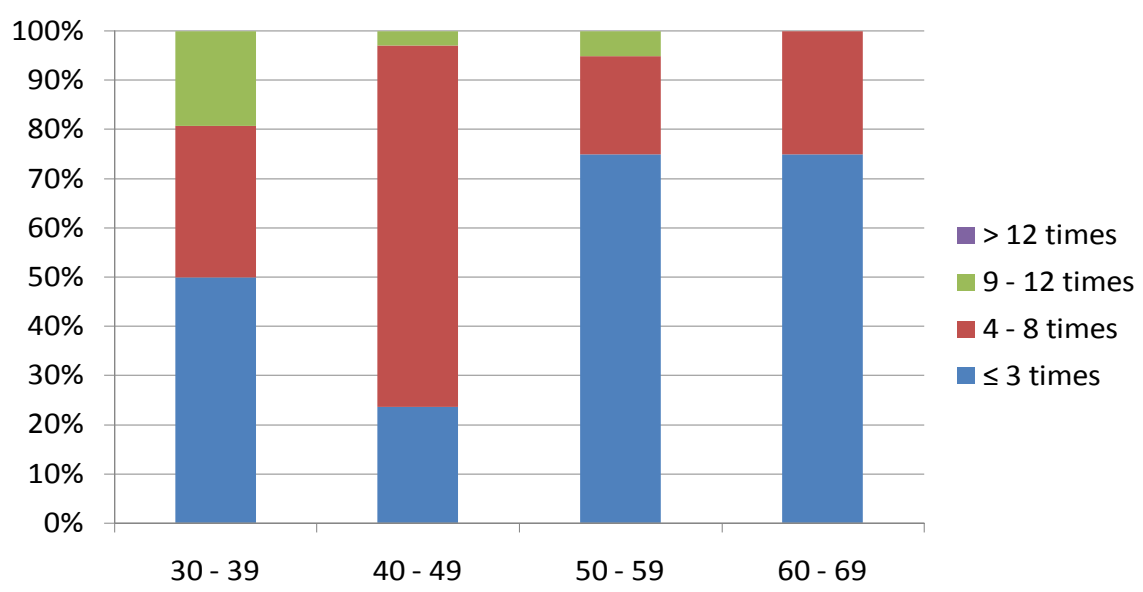

Frequency of sexual intercourse (per month) by different age groups

Figure 1. Relationship between frequency of sexual intercourse and age categories.

\section{Erection hardness score and frequency of sexual intercourse}

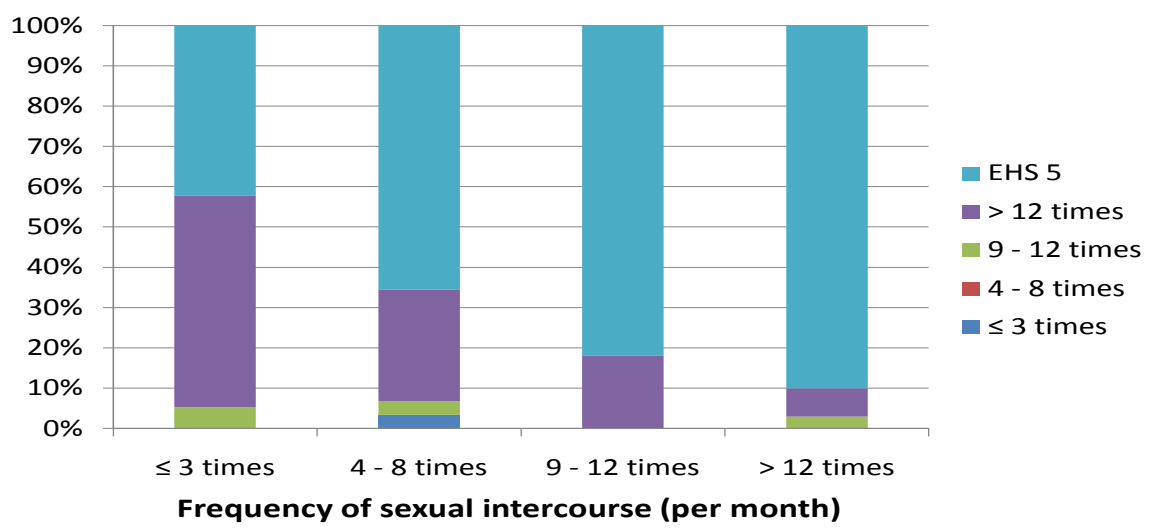

Figure 2. Erection hardness score and frequency of sexual intercourse.

$32.4 \%$ reported by El-Sakke [12] but more than $16.5 \%$ recently reported by Majzoub et al. [22] in a sample of Egyptian patients with type 2 diabetes. In the general population, the prevalence of premature ejaculation varies greatly depending on location and associated medical co-morbidities. The huge variability in the reported prevalence may be due to the different methods with which PE is defined, which include questionnaires, self-reports, and several expert panel definitions [23] [24] [25]. It could also be due to differences in lifestyles among varied populations which may have a direct influence on sexual function and prevalence.

Our study shows a direct relationship between the prevalence of premature 
ejaculation and the frequency of sexual intercourse, that is, less occurrence of premature ejaculation is associated with a decrease in the frequency of sexual intercourse among the participants. This finding is contrary to the thought that frequent sexual intercourse activity may be related to fewer incidence of premature ejaculation because of the thought that those who last longer in bed during vaginal penetration tend to feel good about themselves and may be "bolder" to initiate sexual intercourse with their partners, and conversely, that men with PE might be reluctant to initiate sex, trying to avoid embarrassment. Also, that frequent sexual activity may lead to increased awareness of sensations premonitory to ejaculation, increased ejaculatory threshold, decreased anxiety, and decreased penile sensitivity. Men with early ED may intentionally "rush" sexual intercourse to prevent premature loss of their erection and ejaculate with a brief latency. This may be compounded by the presence of high levels of performance anxiety related to their ED which serves to only worsen their prematurity. However, the finding of increased premature ejaculation with frequent sexual activity may be related to younger age group who are less experienced in sexual acts hence may be associated with performance anxiety leading to rush to ejaculation. It may also be related to pressure to satisfy their wives during sexual activity or the belief that repeated or frequent sexual activity will help overcome premature ejaculation. Men who have low frequencies of sexual activity tend to maximise the few times of sexual activity hence may help reduce incidence of premature ejaculation in them by diminishing performance anxiety i.e. men with low frequency of sexual intercourse would be able to practice to control their ejaculation leading reduced premature ejaculation.

However, there are conflicting data regarding an association between the amount of sexual activity and PE, with some studies showing that PE is associated with less frequent sexual activity [26] [27] [28] and others finding no such relationship [29]. The mechanism underlying such a relationship has yet to be specified, but some have opined that premature ejaculation could be more common in younger men who are finding out about sexual activity and sexual relationships, and in men of all ages after a long period of abstinence [22].

There was no significant association found between age and PE, that is, the prevalence of PE was similar across the age groups, however the prevalence of ED as assessed with EHS increased with age leading to more sexual activity among the younger age groups compared to the elderly. This lack of association of PE with age was similar to that found in the PE Prevalence and Attitudes survey and the prevalence study of sexual dysfunction in the United States. Laumann et al. [2] reported that a history of difficulty with erections was an independent predictor of early ejaculation in a global study, hence, was conjectured that $\mathrm{PE}$ was related to ED.

Fasting blood sugar significantly predicted low EHS and consequently PE in our study, that is, diabetic men with PE has higher fasting blood glucose than the men without PE. This is similar with higher prevalence of PE noted in men with diabetes in similar study [22]. The associations between PE and diabetes have 
been postulated to be due to neurologic, neurotransmitter or psychologic dysfunctions or a combination of factors [30]. It may also be due to diabetes microvascular complications such as neuropathy or diabetic autonomic dysfunctions both of which may contribute to PE since ejaculation largely depend on intact autonomic nervous system, and neurotransmitters [31].

This study has obvious limitation of a sample size but difficulty among our patients to volunteer information about their sexual history was responsible. Our patients were significantly younger in age, a factor that further strengthen our findings for possible generalizations as it minimizes the influence of age in the occurrence of sexual dysfunction which is possibly affected by increasing age. The strength of this study also lied in it being the first reported evaluation of premature ejaculation and erectile dysfunction using both PEDT and EHS in this environment. Study with larger number of participants incorporating psychological assessment is recommended in future. Furthermore, participants were also controlled for presence of other medical conditions or use of some medications that can also affect the prevalence of $\mathrm{Ed}$ and/or PE.

\section{Conclusion}

This study demonstrated a high occurrence of premature ejaculation among patients with diabetes. It also showed that occurrence of PE correlated with increased severity of ED. Diabetic patients reported higher incidence of PE with increased severity of ED. The average fasting blood glucose level was a predictive factor for occurrence of PE in this cohort. The possible aetiologic factors can explain this relationship, include diabetic complications including microvascular and autonomic dysfunctions but further clinical research and assessment are needed to help unveil this observation.

\section{Conflicts of Interest}

The authors declare no conflicts of interest regarding the publication of this paper.

\section{References}

[1] McMahon, C.G., Althof, S., Waldinger, M.D., et al. (2008) An Evidence-Based Definition of Lifelong Premature Ejaculation: Report of the International Society for Sexual Medicine Ad Hoc Committee for the Definition of Premature Ejaculation. BJU International, 102, 338-350. https://doi.org/10.1111/j.1464-410X.2008.07755.x

[2] Laumann, E.O., Nicolosi, A., Glasser, D.B., Paik, A., Gingell, C., Moreira, E. and Wang, T. (2005) Sexual Problems among Women and Men Aged 40-80 y: Prevalence and Correlates Identified in the Global Study of Sexual Attitudes and Behaviors. International Journal of Impotence Research, 17, 39-57. https://doi.org/10.1038/sj.ijir.3901250

[3] Laumann, E.O., Paik, A. and Rosen, R.C. (1999) Sexual Dysfunction in the United States: Prevalence and Predictors. JAMA, 281, 537-544. https://doi.org/10.1001/jama.281.6.537

[4] Porst, H., Montorsi, F., Rosen, R.C., Gaynor, L., Grupe, S. and Alexander, J. (2007) 
The Premature Ejaculation Prevalence and Attitudes (PEPA) Survey: Prevalence, Comorbidities, and Professional Help-Seeking. European Urology, 51, 816-824. https://doi.org/10.1016/j.eururo.2006.07.004

[5] Montague, D.K., Jarow, J., Broderick, G.A., et al. (2004) AUA Erectile Dysfunction Guideline Update Panel. AUA Guideline on the Pharmacologic Management of Premature Ejaculation. Journal of Urology, 172, 290-294. https://doi.org/10.1097/01.ju.0000132159.61156.ea

[6] Carson, C. and Gunn, K. (2006) Premature Ejaculation: Definition and Prevalence. International Journal of Impotence Research, 18, 5-13. https://doi.org/10.1038/sj.ijir.3901507

[7] International Diabetes Federation (2013) IDF Diabetes Atlas. 6th Edition, Brussels.

[8] Thomas, A.M. and LoPiccolo, J. (1994) Sexual Functioning in Persons with Diabetes: Issues in Research, Treatment, and Education. Clinical Psychology Review, 14, 61-86. https://doi.org/10.1016/0272-7358(94)90048-5

[9] Maria, L.I. (2012) Sexual Dysfunction in Men with Type 2 Diabetes. Postgraduate Medical Journal, 88, 152-159. https://doi.org/10.1136/postgradmedj-2011-130069

[10] Hakim, L.S. and Goldstein, I. (1996) Diabetic Sexual Dysfunction. Endocrinology \& Metabolism Clinics of North America, 25, 379-400. https://doi.org/10.1016/S0889-8529(05)70329-7

[11] Thomas, A.M. and LoPiccolo, J. (1994) Sexual Functioning in Persons with Diabetes: Issues in Research, Treatment, and Education. Clinical Psychology Review, 14, 61-86.

[12] El-Sakka, A.I. (2003) Premature Ejaculation in Non-Insulin Dependent Diabetic Patients. International Journal of Andrology, 26, 329-340.

https://doi.org/10.1111/j.1365-2605.2003.00433.x

[13] Lindau, S.T., Tang, H., Gomero, A., Vablie, A., Huang, E.S., Drum, M.L., et al. (2010) Sexuality among Middle Age and Older Adults with Diagnosed and Undiagnosed Diabetes: A National, Population-Based Study. Diabetes Care, 33, 2202-2210. https://doi.org/10.2337/dc10-0524

[14] American Diabetes Association (ADA) (2011) Standard of Medical Care in Diabetes 2011. Diabetes Care, 34, S11-S61. https://doi.org/10.2337/dc11-S011

[15] Mulhall, J.P., Althof, S.E., Brock, G.B., Goldstein, I., Jünemann, K.-P. and Kirby, M. (2007) Erectile Dysfunction: Monitoring Response to Treatment in Clinical Practice-Recommendations of an International Consensus Panel. The Journal of Sexual Medicine, 4, 448-464. https://doi.org/10.1111/j.1743-6109.2007.00441.x

[16] Goldstein, I., Lue, T.F., Padma-Nathan, H., Rosen, R.C., Steers, W.D. and Wicker, P.A. (1998) Oral Sildenafil in the Treatment of Erectile Dysfunction. The New England Journal of Medicine, 338, 1397-1404. https://doi.org/10.1056/NEJM199805143382001

[17] Cappelleri, J.C. and Stecher, V.J. (2008) An Assessment of Patient-Reported Outcomes for Men with Erectile Dysfunction: Pfizer's Perspective. International Journal of Impotence Research, 20, 343-357. https://doi.org/10.1038/ijir.2008.8

[18] (2000) Diagnostic and Statistical Manual of Mental Disorders. Fourth Edition, Text Revision: DSM-IV-TR, American Psychiatric Association, Washington DC, 554.

[19] Symonds, T., Perelman, M.A., Althof, S., Giuliano, F., Martin, M., May, K., et al. (2007) Development and Validation of a Premature Ejaculation Diagnostic Tool. European Urology, 52, 565-573. https://doi.org/10.1016/j.eururo.2007.01.028

[20] Kam, S.C., Han, D.H. and Lee, S.W. (2011) The Diagnostic Value of the Premature 
Ejaculation Diagnostic Tool and Its Association with Intravaginal Ejaculatory Latency Time. The Journal of Sexual Medicine, 8, 865-871. https://doi.org/10.1111/j.1743-6109.2010.02151.x

[21] Tang, D.D., et al. (2018) Validity of Premature Ejaculation Diagnostic Tool and Its Association with International Index of Erectile Function-15 in Chinese Men with Evidence-Based-Defined Premature Ejaculation. Asian Journal of Andrology, 20, 19-23. https://doi.org/10.4103/aja.aja 917

[22] Majzoub, A., Arafa, M., Al-Said, S., et al. (2016) Premature Ejaculation in Type II Diabetes Mellitus Patients: Association with Glycemic Control. Translational Andrology and Urology, 5, 248-254. https://doi.org/10.21037/tau.2016.03.11

[23] Serefoglu, E.C., Yaman, O., Cayan, S., et al. (2011) Prevalence of the Complaint of Ejaculating Prematurely and the Four Premature Ejaculation Syndromes: Results from the Turkish Society of Andrology Sexual Health Survey. The Journal of Sexual Medicine, 8, 540-548. https://doi.org/10.1111/j.1743-6109.2010.02095.x

[24] Ago, J., Zhang, X., Su, P., et al. (2013) Prevalence and Factors Associated with the Complaint of Premature Ejaculation and the Four Premature Ejaculation Syndromes: A Large Observational Study in China. The Journal of Sexual Medicine, 10, 1874-1881. https://doi.org/10.1111/jsm.12180

[25] McMahon, C.G., Lee, G., Park, J.K., et al. (2012) Premature Ejaculation and Erectile Dysfunction Prevalence and Attitudes in the Asia-Pacific Region. The Journal of Sexual Medicine, 9, 454-465. https://doi.org/10.1111/j.1743-6109.2011.02507.x

[26] Godpodinoff, M.L. (1989) Premature Ejaculation: Clinical Subgroups and Etiology. Journal of Sex \& Marital Therapy, 15, 130-134. https://doi.org/10.1080/00926238908403817

[27] Williams, W. (1984) Secondary Premature Ejaculation. Australian \& New Zealand Journal of Psychiatry, 18, 333-340. https://doi.org/10.3109/00048678409158795

[28] Spiess, W.F., Geer, J.H. and O’Donohue, W.T. (1984) Premature Ejaculation: Investigation of Factors in Ejaculatory Latency. Journal of Abnormal Psychology, 93, 242-245. https://doi.org/10.1037/0021-843X.93.2.242

[29] Strassberg, D.S., Kelly, M.P., Carroll, C. and Kircher, J.C. (1987) The Psychophysiological Nature of Premature Ejaculation. Archives of Sexual Behavior, 16, 327-336. https://doi.org/10.1007/BF01542142

[30] Saenz de Tejada, I. and Goldstein, I. (1988) Diabetic Penile Neuropathy. Urologic Clinics of North America, 15, 17-22.

[31] Francomano, D., Donini, L.M., Lenzi, A. and Aversa, A. (2013) Peripheral Arterial Tonometry to Measure the Effects of Vardenafil on Sympathetic Tone in Men with Lifelong Premature Ejaculation. International Journal of Endocrinology, 2013, Article ID: 394934. https://doi.org/10.1155/2013/394934 